\title{
On the Style Switching Behavior of Mutual Fund Managers ${ }^{\S}$
}

\author{
Bart Frijns \\ Auckland University of Technology, Auckland, New Zealand \\ Auckland Centre for Financial Research
}

Aaron Gilbert

Auckland University of Technology, Auckland, New Zealand

Auckland Centre for Financial Research

\begin{abstract}
Remco C. J. Zwinkels*
Erasmus School of Economics, Erasmus University Rotterdam, The Netherlands

Auckland Centre for Financial Research
\end{abstract}

${ }^{\S}$ We would like to thank seminar participants at Monash University for their useful comments and suggestions.

*Corresponding author. Erasmus University Rotterdam, Erasmus School of Economics. P.O.Box 1738, 3000DR, Rotterdam, The Netherlands. E: zwinkels@ese.eur.nl; T: +31 10408 1428; F: +31 104089165. 


\title{
On the Style Switching Behavior of Mutual Fund Managers
}

This Version: July 2012

\begin{abstract}
This paper develops an empirically testable model that is closely related to theoretical model for style switching behavior of Barberis and Shleifer (2003). We implement this model to examine the style switching behavior of US domestic equity mutual fund managers. Using monthly data for 2,044 mutual funds over the period 1961-2010, we find strong evidence for style switching behavior: on average nearly $53 \%$ of the funds in our sample engage in style switching. Overall, we find that growth funds tend to behave more as positive feedback (momentum) traders, whereas value funds tend to behave more as negative feedback (contrarian) traders. Linking the style switching behavior to fund characteristics, we typically find that funds that engage more aggressively in style switching tend to be younger and have higher total expense ratios. Linking the style switching behavior to risk-adjusted performance, we find no evidence of the ability of style switching to generate positive alpha.
\end{abstract}

JEL Codes: C22; C58; G11

Keywords: Mutual Fund Managers; Style Switching; Feedback Trading. 


\section{Introduction}

One of the great success stories in finance is the development of the mutual fund industry. This industry has seen tremendous growth in the past decades, both in terms of invested capital and number of funds. With this enormous growth in number and diversity, many funds classify themselves into investment styles to provide investors with some information on the asset allocation of the fund. These styles have flown out of the popularity of certain investment strategies among mutual fund investors, such as growth or value stocks and small or large cap stocks (Teo and Woo, 2004). Given that these strategies are selected for their perceived ability to produce positive alpha, pursuing such a strategy should play a major role in determining the returns that a fund produces from following the strategy. However, as Barberis and Shleifer (2003) point out, the returns to particular styles are not constant and can be thought of as following a life cycle, where returns may go from outperforming initially to underperforming as market conditions change or the characteristic is priced out of the market. As such, returns for funds identifying with a particular style will be driven, to a large degree, by the performance of the style.

Of interest is the effect that such changes in style performance have on funds that are committed to a particular style. Competition between mutual funds for fund flow is fierce and is largely driven by the recent performance of the fund (Sirri and Tufano, 1998). As a result, there are considerable incentives for funds to outperform other funds within the same asset style. ${ }^{1}$ As fund returns are largely driven by the proclaimed investment style of the fund, one way to achieve outperformance is by strategically (and temporarily) deviating from the

\footnotetext{
${ }^{1}$ Brown, Harlow, and Starks (1996), for instance, show that mutual funds engage in so-called tournament behavior, where funds take on additional risks in later evaluation periods if they are being outperformed by peers.
} 
proclaimed investment style and increasing exposure to styles that are expected to perform better. This has become known as style timing or style switching.

In this paper, we examine the style switching behavior of US mutual fund managers using the framework of Barberis and Shleifer (2003). Barberis and Shleifer (2003) propose a theoretical model of style investing, where individual investors classify assets into styles and allocate their investments at the style level. Barberis and Shleifer (2003) further propose a mechanism of how investors allocate money to particular investment styles and suggest that investor act as feedback traders, comparing the relative past performance of the different investment styles. This model can explain several stylized facts observed in financial markets, such as style momentum and excess comovement of assets within a style. The empirical predictions of the model proposed by Barberis and Shleifer (2003) have been validated by several studies, e.g. Teo and Woo (2004) and Froot and Teo (2008). However, we are not aware of any study that estimates an empirical model along the lines of Barberis and Shleifer (2003). Based on Froot and Teo (2008), who find that institutional investors also allocate more at the style level than at the individual stock level, we postulate that fund managers display similar behavior as individual investors in terms of their asset allocation to different styles, and acting as feedback traders. As such, we connect to several lines of literature, such as style investing, style switching, as well as and investor behavior.

We implement the model of Barberis and Shleifer (2003) empirically using the framework proposed by Brock and Hommes (1997). Brock and Hommes (1997) consider a market for a single asset, where investors can switch between different trading strategies over time conditional on their relative performance in recent periods. Switching between these strategies occurs by means of a multinomial choice function. This function has several 
desirable features. First, it introduces continuous time-varying exposures to different investment styles and therefore allows us to modify a model with static exposures into a dynamic one. Second, this function is very flexible and can include any variable that may trigger fund managers to change their investment style. We use relative past performance, following Barberis and Shleifer (2003) and Brock and Hommes (1998), to assess whether fund managers engage in feedback trading. Third, this function leads to a parsimonious model specification, which (in the simplest specification) only consumes one additional degree of freedom compared with a static specification.

We use the survivorship-free CRSP mutual fund database over the period December 1961September 2010 to examine the switching behavior in US domestic equity funds. We classify funds into different styles based on their Lipper Classification code based on size (Large, Multi, Mid, and Small cap) and value-growth orientation (Value, Centre, and Growth). This produces a $4 \times 3$ matrix of 12 different styles. To assess the switching behavior of fund managers, we obtain four benchmark portfolios/styles: large-value, small-value, largegrowth, and small-growth from Kenneth French's website. ${ }^{2}$ The selection of these four styles allows us to examine the switching behavior of fund managers in both the size and valuegrowth dimensions jointly and separately.

We find strong evidence for feedback-induced style switching in our sample, over $50 \%$ of the funds in our most basic specification. These results corroborate the findings of Froot and Teo (2008), who also find strong support for style-level trading by US domestic equity fund managers. Interestingly, we find that fund managers not only act as positive feedback or

\footnotetext{
${ }^{2}$ Data are available from http://mba.tuck.dartmouth.edu/pages/faculty/ken.french/index.html. The selection of these four styles allows for switching in the size and value-growth dimension.
} 
momentum traders (as suggested by Barberis and Shleifer, 2003), but there is also a considerable number of fund managers that act as negative feedback or contrarian traders. ${ }^{3}$ This findings has also been observed in the trading behavior of individual investors in index funds (Goetzmann and Massa, 2002) and style funds (Blackburn et al., 2011), but to date has not been documented in the trading behavior of fund managers.

Consistent with Froot and Teo (2008) and along the lines of Barberis and Shleifer (2003), we find strong support for the existence of so-called twin styles, ${ }^{4}$ where investors switch between styles at opposite ends of the spectrum. For the funds that engage in style switching, the majority tends to do so in both the value-growth and the size dimension.

In addition, we find that the style switching behavior, i.e. being a positive or negative feedback trader highly depends on the investment style, where managers of growth funds tend to base their switching strategy on a positive feedback rule (i.e. increasing exposure to styles that have performed relatively well in the recent past), whereas managers of value funds tend to base their switching strategy on a negative feedback rule (i.e. increasing exposure to styles that have performed relatively poor in the recent past). This has been observed in the trading behavior of individual investors (Blackburn et al., 2011) but has not yet been documented in the behavior of institutional investors.

When we examine the relationship between fund characteristics and switching behavior in a cross-sectional test, we find that younger mutual funds and mutual funds with higher total

\footnotetext{
${ }^{3}$ We follow Goetzmann and Massa (2002) in our definitions of momentum and contrarian traders, where a momentum trader is defined as a trader who buys after a recent price increase and a contrarian trader buys after a recent price decrease.

${ }^{4}$ Twin styles refer to the asset allocation decision, where an increase in the allocation to, say, value stocks is financed by a decrease in the allocation to its twin style, growth stocks, etc.
} 
expense ratios engage in more aggressive switching behavior. For funds that switch aggressively in the size dimension, we also find a significantly positive relationship with the turnover of the fund.

Finally, we evaluate whether style switching leads to increased outperformance for mutual funds. ${ }^{5}$ We do this by obtaining risk-adjusted outperformance (alpha) from the Carhart (1997) 4-factor model and regress this alpha on the degree by which funds switch and several other fund characteristics. Consistent with Brown et al. (2011), we find that style switching does not lead to outperformance. We do, however, find that when funds that apply a positive feedback rule in the "short run" (1 to 6 months), there is no significant impact on alpha. However, when fund managers apply such a strategy in the "long run" (7 to 12 months) there is a significant deterioration in outperformance. In contrast, fund managers that apply a negative feedback trading rule in the "short run" see a significant deterioration in outperformance, whereas those that apply such a strategy in the "long run" see no effect on outperformance.

Our work is related to several empirical studies on style investing. It closely relates to Froot and Teo (2008), who examine style investing for institutional investors (US domestic equity funds) and show that institutional investors indeed allocate their investments at the style level. They also provide empirical evidence for allocations being made according to the "twin-styles" conjecture of Barberis and Shleifer (2003), where increased allocations towards

\footnotetext{
${ }^{5}$ Several studies have examined style timing in mutual funds, however, evidence of whether this style timing is profitable is mixed. For example, Swinkels and Tjong-A-Tjoe (2007) examine three styles, market timing, value-growth and size, and find profitable switching with regards to market timing and value-growth but not size. Budiono and Martens (2009) test a model with all three styles, market timing, value-growth and size, and find that managers that time styles generate significant outperformance. Grinblatt et al. (1995) find outperformance of momentum traders compared to other funds. By contrast, Brown, Harlow, and Zhang (2011) shows that funds switch aggressively, i.e. have high style volatility, underperform relative to fund with less style volatility on a risk adjusted basis.
} 
small caps tend to be financed by decreased allocations towards large caps, etc. We confirm this finding of Froot and Teo (2008) and extend their work by showing that fund managers engage in twin style trading either as positive or negative feedback traders. This largely depends on the investment style of the fund.

In addition, our paper relates to Brown et al. (2011) who study style switching (measured by style volatility) and relate this to risk-adjusted outperformance of mutual funds. In line with Brown et al. (2011), we confirm that funds that switch aggressively between styles have lower risk adjusted performance. We extend their work by showing that style volatility can be explained by positive and negative feedback trading and show that both these strategies have a different impact on risk adjusted outperformance (positive feedback trading being worse when used with longer look back periods and negative feedback trading being worse when used with shorter look back periods). Wermers (2012) further notes that style drift, for a significant part, is caused by active management. In addition, Wermers (2012) finds that managers tend to be "style chasers"; this is in line with our findings of feedback trading at the style level.

Finally, this paper is closely related to several studies on investor behaviour (i.e. feedback trading). An important contribution in this respect comes from Grinblatt, Titman and Wermers (1995), who find that $77 \%$ of mutual funds have a tendency to buy past winning stocksBange (2000) shows that stock portfolio adjustments of individual investors reflect past market movements, consistent with positive feedback trading. In addition, Keim and Madhaven (1995) document both momentum and contrarian trading by institutional investors. Choe, Kho, and Stulz (1999) and Froot, O’Connell, and Seasholes (2001) report feedback trading by institutional investors at the country level. Goetzmann and Massa (2002) 
examine the trading behaviour of individual investors in index funds and find that some investors act as positive feedback traders (who they label 'momentum traders') and some as negative feedback traders (who they label 'contrarian traders'). In an extension, Blackburn et al. (2011) study the trading behaviour of individual investors in style and multi-style funds (value, growth and value-growth funds). They find that investors adopt different trading strategies depending on the characteristics of the assets being traded, where growth investors tend to follow momentum buy strategies and value investors tend to follow a contrarian buy strategy. We contribute to this literature by showing that institutional investors also follow momentum and contrarian trading strategies, and, in line with Blackburn et al. (2011) we find that managers of growth funds follow more momentum strategies, whereas managers of value funds follow more contrarian strategies.

The remainder of the paper is organized as follows. Section 2 presents our feedback trading model. In Section 3, we explain the data and methodology applied to estimate the model, and Section 4 presents the results. Section 5 concludes.

\section{Model}

Barberis and Shleifer (2003) propose a model of style investing, where the market is populated by investors who can switch between investment styles based on the past relative performance of these styles (referred to as switchers) and fundamental traders, who act as arbitrageurs. In this section, we develop an empirically testable model along the lines of Barberis and Shleifer (2003), where, instead of individual investors, mutual fund managers switch between investment styles based on the styles' relative past performance. 
According to Barberis and Shleifer (2003), switchers allocate more capital to a particular style if it performed relatively well in the recent past and finance this by allocating less to styles with relatively poor past performance. These switchers are assumed to have a specific look-back period over which they compare the relative performance of the different investment styles. They further have a specific degree of style persistence (i.e. how sensitive they are to differences in relative past performances of the investment styles). A further feature is that although investors are willing to switch between styles, they are less willing to switch between asset classes, i.e. investors may be willing to switch between value and growth, but are less willing to switch between, e.g., equities and bonds. This implies that the switching between styles is mostly self-financed within a specific asset class. Finally, Barberis and Shleifer (2003) suggest that switchers choose to switch between so-called twinstyles, where an increased allocation to growth stocks is financed by a decreased allocation to value stocks and an increased allocation to small-cap stocks is financed by a decreased allocation to large-cap stocks, etc.

We empirically implement the model of Barberis and Shleifer (2003) using a discrete choice model along the lines of Manski and McFadden (1981) and concepts of the adaptive rational equilibrium framework proposed by Brock and Hommes (1997). Brock and Hommes (1997) propose a model where economic agents use predictors (which are functions of past information) and choose between these predictors using a discrete choice model, selecting the predictor (or putting more faith in the predictor) that has produced the highest profit or the lowest forecast error in the recent past. This generates a dynamics where, over time, agents switch between different predictors and adjust their demand for assets accordingly. ${ }^{6}$ The

\footnotetext{
${ }^{6}$ See Brock and Hommes (1998) for the complex dynamics that such a model can generate in asset prices.
} 
degree to which these agents switch between different predictors is controlled by a so-called intensity of choice parameter, and captures the agents' sensitivity to differences in the profits or forecast errors of the different predictors.

At each point in time, fund managers examine the past performance of $K$ different investment styles, where $k=1, \ldots, K$. We define the past performance of style $k$ as,

$$
\pi_{t-1}^{k}=\sum_{j=1}^{J} r_{t-j}^{k}
$$

where $r_{t}^{k}$ is the return on investment style $k$ in period $t, \pi_{i t-1}^{k}$ is the past performance measure of investment style $k$ in period $t-1$, and $j$ is the number of periods that the fund manager $\operatorname{looks} \operatorname{back}(j=1, \ldots, J){ }^{7}$

Following Brock and Hommes (1997, 1998), we assume that the switching between styles follows a multinomial switching rule which compares the relative performance of the various investment styles. According to this switching rule, the weights that a manager $i$ puts on investment style $k$ is defined as

$$
w_{i t \mid t-1}^{k}=\frac{\exp \left\{\gamma_{i}\left(\pi_{t-1}^{k}\right)\right\}}{\sum_{k} \exp \left\{\gamma_{i}\left(\pi_{t-1}^{k}\right)\right\}}=\frac{1}{1+\sum_{l \neq k} \exp \left\{\gamma_{i}\left(\pi_{t-1}^{l}-\pi_{t-1}^{k}\right)\right\}},
$$

\footnotetext{
${ }^{7}$ Barberis and Shleifer (2003) use a geometric decay process to capture the memory of investors. We apply a discrete measure following Blackburn et al. (2011). 
where $w_{i t t-1}^{k}$ is the weight fund manager $i$ puts on strategy $k$ at time $t$, conditional on time $t-$ 1 information, and $\gamma_{i}$ is the intensity of choice parameter, which captures the manager's sensitivity to the past profits of different investment styles and determines the aggressiveness by which the fund manager switches between different investment styles. For instance, if $\gamma_{i}=$ 0 , the fund manager does not respond to differences in relative profitability, and in this case $w_{i t t-1}^{k}=w^{k}$. At the other extreme, if $\left|\gamma_{i}\right| \rightarrow \infty$ the fund manager will fully allocate his investments to the style that has had the highest relative performance. A positive value for $\gamma_{i}$ indicates that the fund manager puts more weight on the style that performed relatively well in the recent past and therefore behaves as a positive feedback (momentum) trader. A negative value for $\gamma_{i}$ indicates that the fund manager acts as a negative feedback (contrarian) trader. $^{8}$

The switching rule defined in Equation (2) has several empirical advantages. First, it ensures that weights add up to unity. In other words, if a certain style performs better than another, capital is added to the former at the expense of the latter (this conforms with Barberis and Shleifer (2003), who suggest that the switching between styles is self-financed within a specific asset class). Second, the multinomial switching rule guarantees that each weight is bounded between zero and one, implying that fund managers cannot switch from a long to a short position and vice versa. This is a reasonable assumption as we are examining US domestic equity funds, which generally only enter into long positions. ${ }^{9}$

\footnotetext{
${ }^{8}$ See also Goetzmann and Massa (2002) and Blackburn et al. (2011) who use a similar definition of momentum and contrarian traders and identify the presence of both types of traders among individual investors.

${ }^{9}$ In addition, this specification only consumes one additional degree of freedom whereas several alternatives typically consume one additional degree of freedom per style; see e.g. Swinkels and Tjong-a-Tjoe (2007).
} 
Based on the stated investment style of the fund and the past performance of all styles, the fund manager allocates capital. The return of the fund can be explained by the returns on the different styles and the exposures the fund manager has to each investment style, i.e.,

$$
r_{i t}=\alpha_{i}+\sum_{k=1}^{K} w_{i t t-1}^{k} \beta_{i}^{k} r_{t}^{k}+\varepsilon_{i t}
$$

where $r_{i t}$ is the return of fund $i$ at time $t, \alpha_{i}$ captures the out- or underperformance over the investment styles, and $\beta_{i}^{k}$ captures the unconditional exposure to each investment style $k$. We include unconditional exposures in this equation as fund managers typically classify themselves into a particular investment style. For example, if a fund classifies itself as a growth fund, then we expect that, unconditionally, there will be a greater exposure to the growth investment style than to other styles. Including $\beta_{i}^{k}$ in Equation (3) therefore allows a fund to take an unconditional exposure to its stated investment style, whereas $w_{i t t-1}^{k}$ allows for deviations from these unconditional exposures.

\section{Data}

We estimate the model presented in Section 2 using data from the CRSP Mutual Fund Database. This is a survivorship bias free database that contains monthly mutual fund data from 1961 onwards. Our data run from December 1961 to September 2010. We collect data for retail funds with more than 10mln USD assets under management that have a Domestic Equity focus and exclude Index tracking funds. We remove funds with less than 36 observations to ensure that we can obtain meaningful estimates of our coefficients. Before 
estimating the model, we classify funds into investment styles based on the Lipper classification code. We focus on twelve styles: large cap value equity (LCVE); large cap core equity (LCCE); large cap growth equity (LCGE); multi cap value equity (MLVE); multi cap core equity (MLCE); multi cap growth equity (MLGE); mid cap value equity (MCVE); mid cap core equity (MCCE); mid cap growth equity (MCGE); small cap value equity (SCVE); small cap core equity (SCCE); small cap growth equity (SCGE). Next, we check whether a fund's investment style is consistent with its Lipper classification. To do this we follow Annaert and van Campenhout (2007). For each fund, we estimate a regression of the fund's excess returns on the excess returns of the market, the SMB factor and the HML factor. ${ }^{10}$ For this regression, we require the $R^{2}$ to be at least $50 \%$, and we require the factor loadings to be consistent with the fund style (i.e. positive exposure to the excess market return, and a positive loading on SMB if the fund classifies itself as small cap, or a negative loading if it classifies itself as large cap, etc.). This leaves us with 2,044 unique US domestic equity funds. ${ }^{11}$

\section{INSERT TABLE 1 HERE}

In Table 1, we report summary statistics for the mutual funds in our sample. As can be seen, all fund types are well represented, with mid cap value equity having the least number of funds in the sample (96) and multi cap centre equity having the greatest number of funds in the sample (326). The median average return shows considerable variation over the various investment styles with large cap growth equity having the lowest average return per month of $0.530 \%$ (about $6.5 \%$ p.a.), and small cap centre equity having the highest average return of

\footnotetext{
${ }^{10}$ We use the data provided on Kenneth French's website.

${ }^{11} \mathrm{We}$ also filter all duplicate funds from our sample. Typically, these are identical funds but with different fee structures (A, B, C funds). 
$1.024 \%$ per month (about $13 \%$ p.a.). The pattern in returns clearly reveals the presence of a size effect, where small cap funds generally outperform larger cap funds. The growth effect is less pronounced in this table, in two of the size classes (large and mid cap) value outperforms growth, while it is the reverse in the other two size classes. The standard deviations also show considerable variation over the different investment styles, and we generally find that the investment styles with higher risk also yield higher average returns. Minimum and maximum values reveal that returns can vary widely over time, with a lowest minimum return of $26.89 \%$ and a highest maximum return of $20.71 \%$. These numbers also highlight that there is some negative skewness in our data. The last column shows the median number of observations (months) per fund. These median values range between 7 to 10 years of data.

In addition to return data, we also obtain data on fund characteristics. We obtain Total Expense Ratio, Fund Age, Total Net Assets, and Turnover from the CRSP mutual fund database.

\section{INSERT TABLE 2 HERE}

In Table 2, we report summary statistics on several fund characteristics. The average Total Expense Ratio (TER) for all funds in the sample is $1.41 \%$. In general, we observe that growth funds have higher TERs than value funds (this was also documented by Carhart (1997)), and that small cap funds charge higher TERs than large caps (a findings also observed by Brown et al., 2011). The average Age of the funds in our sample is 14.24 years, but again we note some variation across the different fund styles. First, we note that centre equity funds tend to be younger than value or growth funds. Second, we note that small cap funds tend to be younger than large cap funds. 
The average size of the funds in our sample is $\$ 418.5$ million, although there is considerable variation in the size of funds. In general, large cap funds tend to be larger than small cap funds. For value-growth, we note that growth funds are larger for the large cap funds, and that value funds are larger for the small cap funds.

When we look at the Turnover of funds, we find an average Turnover ratio of $83.30 \%$, which is again broadly in line with the ratios presented by Carhart (1997) and Brown et al. (2011). In line with these studies, we also find variation in Turnover ratio by style, where growth funds have higher Turnover ratios than value funds, and small cap funds have higher turnover ratios than large cap funds.

To examine the style switching behavior of mutual fund managers, we compare the performance of each mutual fund with the performance of benchmark portfolios. These benchmark portfolios are obtained from Kenneth French's data library. ${ }^{12}$ Instead of using the usual style factors, such as $S M B$ and $H M L$, we use the individual portfolios to construct these factors as our investment styles. In particular, we use the large-value $(L V)$, large-growth $(L G)$, small-value $(S V)$, and small-growth $(S G)$ portfolios. $^{13}$

\section{INSERT TABLE 3 HERE}

In Panel A of Table 3, we present descriptive statistics on the benchmark portfolios. The mean returns show quite some variation across the different styles, which is consistent with

\footnotetext{
${ }^{12}$ http://mba.tuck.dartmouth.edu/pages/faculty/ken.french/data_library.html

${ }^{13}$ For more details on the construction of these portfolios, see Kenneth French's website.
} 
the literature (e.g. Fama and French, 1993). The highest return is observed for the $S V$ benchmark portfolio, with an average return of $1.424 \%$ per month, while the lowest return is observed for the $L G$ portfolio (an average return of $0.816 \%$ per month). We observe that the value effect in returns is more prominent in the small-cap portfolios than in the large-cap portfolios. Standard deviations also differ considerably across the benchmark portfolios, where the highest standard deviation is observed for the $S G$ portfolio (which has the second lowest average return) and is lowest for the $L V$ portfolio. We also find some notable differences in the skewness of the different benchmark portfolios, where large cap firms have more negatively skewed returns than small caps, and value firms have more negatively skewed returns than growth firms.

In Panel B, we report the correlations between the different benchmark portfolios. Since the benchmark portfolios are not long-short strategies which are market risk neutral such as SMB and HML, the correlations are quite high, but not so high that they will cause multicollinearity issues. The highest correlation is between $S V$ and $S G(0.8838)$ and lowest between the $S G$ and $L V$ portfolios (0.7117).

\section{Results}

In this section, we present the results of the model presented in Section 2. We start by presenting results for a specification with constant style exposures. Next, we report the results for two models where fund managers can 1) switch between all four styles (and e.g. could finance investments in growth stocks by selling small caps), and 2) switch between "twin styles", i.e. between value-growth and large-small separately. We then examine whether the 
switching behavior of fund managers is related to fund characteristics, and whether the style switching behavior affects the risk-adjusted performance of mutual funds.

\subsection{Unconditional Fund Exposures}

To examine whether funds indeed follow their stated investment style, we run a regression of the excess returns of a fund on the different investment styles, i.e.,

$$
r_{i t}=\alpha_{i}+\beta_{i}^{S V} r_{t}^{S V}+\beta_{i}^{S G} r_{t}^{S G}+\beta_{i}^{L V} r_{t}^{L V}+\beta_{i}^{L G} r_{t}^{L G}+\varepsilon_{i t}
$$

where $r_{t}^{S V}, r_{t}^{S G}, r_{t}^{L V}, r_{t}^{L G}$ are the returns on the small-value, small-growth, large-value and large growth portfolios, respectively. We run this regression for each individual mutual fund.

\section{INSERT FIGURE 1 HERE}

In Figure 1, we plot the unconditional loadings on the different investment styles. This plot clearly shows two patterns emerging. First, we observe that when moving from value to centre to growth, the loadings on $L V$ and $S V$ decrease, while the loadings on $L G$ and $S G$ increase. This suggests that the different investment styles indeed capture the value-growth classification of the funds. Second, when moving from large- to multi- to mid- to small-cap we observe that the loadings on $L V$ and $L G$ decrease, whereas loadings on $S V$ and $S G$ increase. This also suggests that the different investment styles capture the size classification of the funds. The findings in Figure 1 suggest that, unconditionally, funds indeed behave according to their stated investment style. 


\subsection{Style Switching Behavior of Fund Managers}

To examine the style switching behavior of mutual fund managers, we estimate the model described in Section 2. Empirically, we do this in two ways. We first estimate a model where fund managers can switch between all styles, and could, e.g., increase their exposure to the $L G$ style, by lowering their exposure to e.g. the $S V$ style. We refer to this as single switching. Second, we estimate a model where switching occurs according "twin-styles" (see Barberis and Shleifer, 2003), i.e. fund managers can switch within the value-growth dimension and in the small-large dimension. We refer to this as double switching.

For the single switching model, we estimate the following equation,

$$
r_{i t}=\alpha_{i}+w_{i t \mid t-1}^{S V} \beta_{i}^{S V} r_{t}^{S V}+w_{i t \mid t-1}^{S G} \beta_{i}^{S G} r_{t}^{S G}+w_{i t \mid t-1}^{L V} \beta_{i}^{L V} r_{t}^{L V}+w_{i t \mid t-1}^{L G} \beta_{i}^{L G} r_{t}^{L G}+\varepsilon_{i t},
$$

where the weights are computed according to Equation (2), and profits are computed as

$$
\pi_{k t-1}^{S V}=\sum_{j=1}^{J} S V_{t-j}, \pi_{k t-1}^{S G}=\sum_{j=1}^{J} S G_{t-j}, \pi_{k t-1}^{L V}=\sum_{j=1}^{J} L V_{t-j}, \pi_{k t-1}^{L G}=\sum_{j=1}^{J} L G_{t-j}
$$

The model defined in Equations (5) and (6) assumes that fund managers switch between the four different strategies mentioned above.

To examine the relevance and existence of twin styles we further estimate a double switching model, where we allow the switching to occur over size and/or book-to-market, i.e., 


$$
\begin{aligned}
& r_{i t}=\alpha_{i}+w_{i t \mid t-1}^{S I Z E} w_{i t \mid t-1}^{B M} \beta_{1 i} S V_{t}+w_{i t \mid t-1}^{S I Z E}\left(1-w_{i t \mid t-1}^{B M}\right) \beta_{2 i} S G_{t}+ \\
& \left(1-w_{i t \mid t-1}^{S I Z E}\right) w_{i t \mid t-1}^{B M} \beta_{3 i} L V_{t}+\left(1-w_{i t \mid t-1}^{S I Z E}\right)\left(1-w_{i t \mid t-1}^{B M}\right) \beta_{4 i} L G_{t}+\varepsilon_{i t},
\end{aligned}
$$

where $w_{i t \mid t-1}^{S I Z E}$ is the conditional weight on a small cap style and $w_{i t \mid t-1}^{B M}$ is the conditional weight on the value style. These weights are based on the profitability of each style measured as,

$$
\begin{aligned}
& \pi_{k t-1}^{\text {LARGE }}=\sum_{j_{1}=1}^{J_{1}} L V_{t-j_{1}}+L G_{t-j_{1}} \\
& \pi_{k t-1}^{S M A L L}=\sum_{j_{1}=1}^{J_{1}} S V_{t-j_{1}}+S G_{t-j_{1}} \\
& \pi_{k t-1}^{\text {VALUE }}=\sum_{j_{2}=1}^{J_{2}} L V_{t-j_{2}}+S V_{t-j_{2}} \\
& \pi_{k t-1}^{\text {GROWTH }}=\sum_{j_{2}=1}^{J_{2}} L G_{t-j_{2}}+S G_{t-j_{2}}
\end{aligned}
$$

where $\pi_{k t-1}^{L A R G E}$ is the profitability of the large cap investment style, $\pi_{k t-1}^{S M A L L}$ is the profitability of the small cap investment style, $\pi_{k t-1}^{V A L U E}$ is the profitability of the value investment style and $\pi_{k t-1}^{\text {GROWTH }}$ is the profitability of the growth investment style. The weights are again computed according to Equation (2), but since Equation (7) has two different weights, we also estimate two different intensity of choice parameters $\left(\gamma^{S I Z E}\right.$ and $\left.\gamma^{B M}\right)$. We estimate Equation (7) in three ways. First, we set $\gamma^{S I Z E}$ equal to 0 (this allows for switching only in the value-growth dimension). Second, we set $\gamma^{B M}$ equal to 0 (this allows for switching only in the size dimension). Finally, we allow for switching in both direction simultaneously.

In Equations (6) and (8), we select the optimal lag length in the profit function, by estimating the Equations for $j=1$ to 12 and choose the optimal value, $j^{*}$, by selecting the specification 
with the highest log-likelihood. We estimate the switching models introduced in Section 2 for all funds in our sample. However, before presenting the cross-sectional results we first examine one particular fund in detail to better understand the mechanisms of the model.

\subsubsection{The Case of the Oppenheimer Main Street Opportunity Fund}

To provide some intuition on the underlying dynamics generated by our model, we present detailed results for one particular mutual fund. We select the Oppenheimer Main Street Opportunity Fund, CRSP fund number 23076. The fund is classified as multi-cap core-equity, and has data from September 2000 to the end of our sample in September 2010, yielding 120 monthly observations. At the end of the sample period, the fund had $\$ 11.6 \mathrm{mln}$ assets under management and, as such, is a relatively small fund. From the group of funds that have significant switching parameters it is a random choice.

\section{INSERT TABLE 4 HERE}

Table 4 presents the results for the Oppenheimer fund for the static, the single switching, the value and size twin styles and the double "twin styles" switching models. The estimates for the static model reveal that the fund has significant exposures to the $L G$ and $S V$ portfolios, and, to a lesser extent, the $S G$ portfolio. Both the multi-cap and the core-equity character are therefore well represented in this fund. To interpret the magnitude of the $\beta$ 's, we need to divide the estimated values by 4 , because in the static model, $\gamma=0$, giving each weight a value of 0.25 . Hence, a $1 \%$ return in the LG portfolio results in, on average, $1.574 / 4=$ $0.3935 \%$ return to the fund. 
The second column of Table 4 presents the estimation results for the single switching model (Equations (5) and (6)). The results for the $\beta^{\text {'s }}$ remain roughly the same, although $\beta^{S G}$ becomes insignificant in this model. Most importantly, the intensity of choice parameter, $\gamma$, is positive and significant. A Likelihood Ratio test (LR ${ }^{\text {STATIC }}$ ) confirms that the fit of the switching model is significantly better than the static model. ${ }^{14}$ The fact that $\gamma$ is positive suggests that the manager of the Oppenheimer Main Street Fund follows a positive feedback (momentum) strategy. In the best fitting model, the manager ranks the performance of the four benchmark portfolios over the past 12 months, $j^{*}=12$, and allocates capital in accordance with this ranking.

In the next three columns of Table 3 , we present the results for the double switching models (Equations (7) and (8)). The estimated unconditional exposures are relatively unchanged compared with the static model. For the model where we only allow for switching in the value-growth dimension, we find a positive and significant coefficient, indicating that the fund manager acts as a positive feedback trader. The significance is confirmed by the Likelihood ratio test versus the static model, which produces a LR statistic of 5.52. For the switching in the size dimension, we find an insignificant coefficient and also the LR statistic of 1.78 is insignificant. This suggests that there is no switching behavior of this fund in the size dimension. In the last column, we include the double twin style model, where switching can occur in both directions. In this model, we again observe that $\gamma^{B M}$ is significant and $\gamma^{S I Z E}$ is not. The double twin style model performs significantly better than the static model with a LR statistic of 8.10. Finally, we report the LR statistics of the double twin style model versus

\footnotetext{
${ }^{14}$ Note that because of the nonlinearity in the model a t-test may not always indicate whether there is significant evidence for switching. However, a significant increase in the likelihood provides this evidence.
} 
the value and size twin style. The tests show that the double twin style model does not improve significantly on the value twin style model, but does improve significantly on the size twin style model. This leads us to conclude that this fund only display switching behavior in the value-growth dimension and follows a positive feedback trading rule to do this.

\section{INSERT FIGURE 2 HERE}

In Figure 2, we plot the relation between the performance difference for book-to-market and size $\left(\pi^{V A L U E}-\pi^{G R O W T H}\right.$ and $\left.\pi^{L A R G E}-\pi^{S M A L L}\right)$ versus the weight put on value and large cap stocks

$\left(w^{V A L U E}\right.$ and $\left.w^{L A R G E}\right)$ for the double switching model. For both relations, we observe an upward sloping curve. This is because of the positive values for $\gamma^{B M}$ and $\gamma^{S I Z E}$, leading to a positive relation between past performance and current exposure. The line for the size switching is steeper than for the book-to-market switching, because $\gamma^{S I Z E}>\gamma^{B M}$. From Figure 2 , we can deduce that if the value benchmark under- or outperform the growth benchmark by $40 \%$ in the past year, the manager changes the weight on value from about 0.4 to 0.6 . In the size dimension a similar under- or outperformance between large and small caps leads to a change in the weight on large cap from about 0.25 to 0.75 . An interesting observation from Figure 2 is that the value weights are concentrated in the upper right corner, while the size weights are concentrated in the lower left corner. This implies that over this period value, on average, outperformed growth, whereas small caps outperformed large caps.

INSERT FIGURE 3 HERE 
Figure 3 shows the profit differences and the weights in a time series plot, where the upper part of the graph shows the weights, $w^{V A L U E}$ and $w^{L A R G E}$, and the lower part shows the performance difference $\left(\pi^{V A L U E}-\pi^{G R O W T H}\right.$ and $\left.\pi^{L A R G E}-\pi^{S M A L L}\right)$. Clearly, there is substantial time variation in the book-to-market and size weights, ranging roughly from 0.2 to 0.8 . During the years 2001 and 2002, value firms outperformed growth firms, causing the weight on value firms to be high. For the remaining years, the value premium stays slightly positive, causing the book-to-market weight to be slightly above 0.5 , on average. The size premium is closer to zero throughout the sample period. An interesting exception is the peak in 2001, causing the fund manager to increase the weight on large stocks. In addition, from late 2003 to mid 2004 large cap stocks clearly underperform small cap stocks, resulting in a decrease of the weight on large cap stocks to its low of approximately 0.2 .

\section{INSERT FIGURE 4 HERE}

Figure 4 presents a time series plot of the conditional exposures to the four benchmark portfolios, given by the time varying weights $w_{i t}$ multiplied by the unconditional exposures $\beta_{i}{ }^{k}$. The top-left plot shows the conditional beta on the large value portfolio. As observed from Table 3, the unconditional exposure to the $L V$ portfolio was small, and although there is quite some variation in the conditional beta, in absolute terms the exposure remains low. The top-right plot shows the conditional beta for the $L G$ portfolio. Unconditionally, the loading on this portfolio was largest, and we observe that this portfolio also has the largest absolute variation. Over time the exposure to $L G$ ranges from a low of about 0.25 in late 2001- early 2002 and again in early 2004 to a high of 0.9 around the start of 2008 . This suggests that there are large shifts in the exposure of this fund to the $L G$ portfolio. The bottom-left plot shows the conditional beta of the $S V$ portfolio. Again, we note considerable variation in the 
conditional exposure, where the exposure peaks from the middle of 2001 to the middle of 2002 and troughs at the start of 2008. Finally, the bottom-right plot shows the conditional exposure for the $S G$ portfolio. The conditional exposure on the $S G$ portfolio bottoms at the start of 2001 and peaks in the period 2003-2004. Again, this plot show considerable time variation in the conditional exposure to the $S G$ portfolio.

\subsubsection{Do Mutual Funds Switch?}

We estimate the single and twin style switching models for all mutual funds in our sample and present summary statistics in Table 5. We first report the percentage of funds for which the likelihood of the single $\gamma$ model increases significantly at the 5\% level compared with the static model (Panel A). We report the percentage of funds with positive and significant $\gamma$ and negative and significant $\gamma$. Overall, we find considerable improvements in the model fit when allowing for switching behavior of fund managers. We find that there is significant switching for about $53 \%(30 \%+23 \%)$ of the funds in our sample. Most significance in switching is reported for the Mid Cap Value Equity funds (68\%), whereas the least significance is found for the Large Cap Growth Equity funds (44\%).

\section{INSERT TABLE 5 HERE}

We split out the percentage of significant switching into positive significant switching (i.e. where we observe significant positive feedback or momentum trading) and negative switching (where we observe significant negative feedback or contrarian trading). The results reveal several interesting patterns. We observe that, for all size groups, there is considerably more positive feedback trading as we go from value to growth funds. When we look at the results for negative feedback trading, we observe the opposite pattern, i.e. for value funds we 
find most evidence for negative feedback trading, which then decreases for centre and decreases more for growth funds. This clearly suggests that the style switching behavior is style dependent. This finding is interesting in the light of results of Blackburn et al. (2011). Blackburn et al. (2011) find that individual investors follow positive feedback strategies when buying growth funds, but negative feedback strategies when buying value funds, suggesting that individual investors follow different strategies for different styles. Our results suggest that this is not only the case for individual investors, but also for fund managers.

In Panel B of Table 5, we present the results for the double twin-style switching model, where we allow for two different switching parameters. This Panel presents the percentage of funds for which the double switching model yields a significantly higher likelihood than the static model. In total, we find significant switching for about $76 \%$ of the funds in the sample. This number is consistent with Grinblatt et al. (1995), who find that $77 \%$ of funds buy stocks that were past winners. When looking at the difference between positive feedback trading and negative feedback trading, we again observe several patterns. For the switching in the size dimension, we observe that, except for large-cap funds, there is more positive feedback trading for growth funds than for value funds, and more negative feedback trading for value funds than for growth funds. For the switching in the value dimension we find that there is more positive feedback trading for growth funds across all size styles and more negative feedback trading in value funds than growth funds.

In Panel B3 of Table 5, we report results on single versus double twin style switching. The first row in this panel reports the percentage of funds for which the value twin style switching model is the best. Overall, we observe that most of the funds that switch do so in both the value-growth dimension and the size dimension instead of just in one single direction. 
Growth funds engage more often in double switching than do value funds. Interestingly, in the majority of cases funds are not consistent in their choice of applying positive or negative feedback trading with respect to $\mathrm{BM}$ and size switching. This result is consistent with Blackburn et al. (2011), who conclude that positive or negative feedback trading is not a character trait of investors, but determined by the style they are investing in.

\subsection{Style Switching and Fund Characteristics}

Section 4.2 reports evidence of style switching behavior of mutual fund managers. In this section, we examine whether the style switching behavior is related to fund characteristics, specifically, the total expense ratio, age, size and turnover of the fund. We obtain these fund characteristics from CRSP. We run a cross-sectional regression of the absolute style switching parameters on several fund characteristics, i.e.

$$
\left|\gamma_{i}\right|=\beta_{1} \log \left(\text { Age }_{i}\right)+\beta_{2} \log \left(\text { TNA }_{i}\right)+\beta_{3} \text { Turnover }_{i}+\beta_{4} \text { TER }_{i}+\beta_{5} \operatorname{Lag}+\text { StyleDummy }_{i}+\varepsilon_{i},
$$

where $\log \left(A g e_{i}\right)$ is the $\log$ of the median age of the fund, $\log \left(T N A_{i}\right)$ is the $\log$ of the beginning of period size of the fund, ${ }^{15}$ Turnover $_{i}$ is the median share turnover of the fund, $T E R_{i}$ is the total expense ratio of the fund, $\operatorname{Lag}_{i}$ is the number of lags $j^{*}$ that is used to

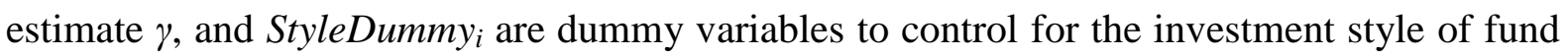
$i$.

\footnotetext{
${ }^{15}$ Note that we include beginning of period Total Net Assets of the funds instead of average fund size to avoid endogeneity issues.
} 
In Table 6, we present the results for Equation (9) using the different $\gamma$ 's, i.e. $\left|\gamma^{S I N G L E}\right|,\left|\gamma^{B M}\right|$ and $\left|\gamma^{\text {SIZE }}\right|$, and report White corrected t-statistics in parentheses. ${ }^{16}$ The first column of Table 6 shows the results for $\left|\gamma^{S I N G L E}\right|$. We find a positive and significant relationship with TER, suggesting that funds that switch more charge higher expense ratios. We further find a negative and significant relationship with age, suggesting that older funds tend to switch less aggressively. There is also a negative and significant relationship with Lag, suggesting that more aggressive switching occurs at shorter look-back periods.

In the next two columns of Table 6 , we separate $\left|\gamma^{\text {SINGLE }}\right|$ into positive and negative values. We do this to assess whether positive or negative feedback trading is affected by specific fund characteristics. We first note that when we split $\left|\gamma^{S I N G L E}\right|$ into positive and negative, TER is no longer significant for the positive feedback traders, but remains significant for negative feedback traders. The negative significance of age remains for both positive and negative feedback trading. We further observe a positive and significant relationship between positive feedback trading and turnover, but an insignificant relationship between negative feedback trading and turnover. This suggests that funds that engage in positive feedback trading trade more actively than negative feedback traders. Finally, we find that the significant relationship between switching behavior and lag observed in the first column is driven by the negative feedback trading funds. Negative feedback traders switch more aggressively based on shorter look-back periods.

\section{INSERT TABLE 6 HERE}

\footnotetext{
${ }^{16}$ We report the results, where we have used the absolute value for gamma for all funds in the sample. We have also run this regression only for funds with significant switching. However, the results are almost identical to those reported in this paper.
} 
In the next set of columns, we report the results for $\left|\gamma^{B M}\right|$. The first column in this block shows that switching in the value-growth dimension is positively related to TER. We further observe significantly negative relationships with Age and Lag. When splitting the switching parameter into positive and negative feedback trading, we observe that TER is only related to positive feedback trading. The negative relationships of $\left|\gamma^{B M}\right|$ with age and lag are observed in both positive and negative feedback trading.

The last block of columns of Table 6 reports the regression results for $\left|\gamma^{\text {SIZE }}\right|$. In the first column, we observe that $\left|\gamma^{S I Z E}\right|$ has a negative and significant relationship with Age, i.e. older funds switch less aggressively in the size dimension. We further find a significant positive relationship with Turnover, suggesting that funds that switch more aggressively in the size dimension have a higher turnover of stocks in their portfolio. When splitting $\left|\gamma^{S I Z E}\right|$ into positive and negative feedback trading, we find that the relationship between $\left|\gamma^{\text {SIZE }}\right|$ and Age is driven by the negative feedback trading funds, i.e. older funds engage in less negative feedback trading (there is no significant relationship between positive feedback trading and age). The relationship between turnover and $\left|\gamma^{S I Z E}\right|$ is driven by the positive feedback trading funds. We further find a significantly negative relationship between lag and positive feedback trading in the size dimension, suggesting that fund managers that follow a momentum strategy in the size dimension trade more aggressively at shorter look-back periods.

\subsection{Outperformance and Style Switching}

The next issue we address is whether the style switching behavior of fund managers is related to the outperformance of the fund. To address this question, we compute Jensen's $\alpha$ for each mutual fund using the four factor Carhart (1997) model, and use this $\alpha$ in the following crosssectional regression, 
$\alpha_{i}=c+\beta_{1} \gamma_{i}^{+}+\delta_{1} \gamma_{i}^{+} \times \operatorname{Lag}_{i}+\beta_{2} \gamma_{i}^{-}+\delta_{2} \gamma_{i}^{-} \times \operatorname{Lag}_{i}+$ FundControls $_{i}+$ StyleDummy $_{i}+\varepsilon_{i}$,

where $\alpha_{i}$ is the constant of the four factor Carhart (1997) model; $\gamma_{i}^{+}$and $\gamma_{i}^{-}$are the style switching parameters for positive feedback trading and negative feedback trading, respectively; Lag is the number of lags that is used to estimate $\gamma$; FundControls $s_{i}$ account for different fund characteristics that may lead to outperformance; and StyleDummy $y_{i}$ are dummy variables to control for the investment style of fund $i$. We include an interaction term between $\gamma$ and Lag as different trading strategies may work better at different look-back periods, i.e. positive feedback (momentum) trading may work better if it is based on switching rules that look back for only a few months (in which case lag is low), whereas negative feedback (contrarian) trading, may work better if the look back period is longer (in which case lag is high).

\section{INSERT TABLE 7 HERE}

In Panel A of Table 7, we report the results for Equation (10). The first column of Panel A shows the results for the single switching parameter. We find a positive and significant relationship between $\gamma+$ and $\alpha$, suggesting that more aggressive positive feedback trading leads to greater risk-adjusted performance. The interaction term of $\gamma+$ with lag has a significantly negative sign, which suggests that as the look-back horizon gets longer, the profitability of positive feedback trading decreases. This is in line with e.g. Jegadeesh and Titman (1993) and Rouwenhorst (1998) (amongst many others) who find that momentum strategies work better when based on short look back horizons. Next, we consider the results 
for $\gamma$-. We find a positive significant impact of $\gamma$ - on the $\alpha$ of the fund. This suggest that the lower (more negative) $\gamma$ - is (i.e. the more aggressively the fund manager acts as a negative feedback trader), the lower the risk-adjusted performance of the fund is. The interaction term of $\gamma$ - with lags yields a negative coefficient, suggesting that the coefficient on $\gamma$-decreases as the look-back horizon increase. The loading on $\gamma$ - becomes negative from 4 lags and onwards. This implies that when fund managers follow a contrarian strategy, their strategy starts to have a positive impact on risk-adjusted performance if they base their switching behavior on longer look-back horizons. For the fund-level control variables, we find a negative relationship between $\alpha$ and Age, Fund Size, Turnover and a negative relationship between $\alpha$ and TER. All these results are consistent with the literature (see e.g. Carhart, 1997).

In the second column of Table 7, we show the results for the switching in the value-growth dimension. We find that the impact of positive feedback trading in this dimension, in general, is positive. However, there is no impact of lags or negative feedback trading.

In the third column, we report the results for the regression of risk-adjusted performance on the switching in the size dimension. This column shows the opposite result of the switching in the value dimension. In this regression, we find a negative relationship between positive feedback trading and risk-adjusted performance. As for the fund controls, there an no notable difference with the results presented in the first column.

In Panel B of Table 7, we report the results of a regression similar to Equation (10), but now split the positive and negative switching parameters into quartiles based on their look-back horizon. We define $\gamma_{1}^{+}, \gamma_{2}^{+}, \gamma_{3}^{+}, \gamma_{4}^{+}$, and $\gamma_{1}^{-}, \gamma_{2}^{-}, \gamma_{3}^{-}, \gamma_{4}^{-}$as the positive and negative 
switching parameters for lags less than 3 months, between 4 and 6 months, between 7 and 9 , and between 10 and 12 months, respectively. The first column, where we assess the relationship between the single switching parameter and the risk-adjusted performance of a fund, shows that there is no risk-adjusted performance due to trading as a positive feedback trader in the short-run, but that there are mainly negative effects for acting like a positive feedback trader in the long-run. The impact of negative feedback trading has the opposite pattern. There is a loss due to negative feedback trading in the short-run, but there are no gains in the long-run. These results broadly confirm findings of Brown et al. (2011), who show that fund with high style volatility (more style switching) perform worse than funds with low style volatility.

In columns 2 and 3, we report the results for the switching in the $\mathrm{B} / \mathrm{M}$ and size dimensions, respectively. For the style switching in the $\mathrm{B} / \mathrm{M}$ dimension, we find insignificant results for the positive feedback trading rules, while we find a significantly negative relationship between risk-adjusted performance and the negative feedback trading rules. For the size dimension, we find that positive feedback trading mostly leads to lower risk-adjusted performance (significantly so in the windows of 4 to 9 months). For the contrarian strategy in this dimension we find mixed results, where there is some evidence of contrarian trading leading to higher risk-adjusted performance in the 4 to 6 month window and leading to lower risk-adjusted performance in the 7 to 9 month window.

\section{Conclusion}

This paper seeks empirical evidence for the style switching model proposed in Barberis and Shleifer (2003). Using a sample of US equity funds, we find strong evidence for feedback 
trading by fund managers. Our results reveal that around $53 \%$ of the funds in our sample display some form of feedback trading. An interesting observation is that slightly more than half of these are negative feedback strategies: increasing (decreasing) the exposure to recent losers (winners). Switching seems to occur predominantly between the value and growth styles, and less so between the small and large cap styles. A higher propensity to switch is found for funds with a higher total expense ratio, younger funds, value funds, and mid-cap funds. Finally, we find that when fund managers apply feedback trading rules 'correctly', i.e. momentum trading in the short run and contrarian trading in the long run, there are no extra gains or losses from this strategy. However, if fund managers apply these rules 'incorrectly', i.e. long-term momentum and short-term contrarian trading, this actually leads to underperformance. 


\section{References}

Annaert, J. and van Campenhout, G., 2007. Time variation in mutual fund style exposures. Review of Finance 11, 633-661.

Bange, M.M., 2000. Do the portfolios of small investors reflect positive feedback trading? Journal of Financial and Quantitative Analysis 35, 239-255.

Barberis, N., Shleifer, A., 2003. Style investing. Journal of Financial Economics 68, 161199.

Blackburn, D., Goetzman, W. and Ukhov, A., 2011. Trading behavior of style and multi-style Investors. Working Paper.

Brock, W. A. and Hommes, C. H., 1997. A rational route to randomness. Econometrica 65, 1059-1095.

Brock, W. A. and Hommes, C. H., 1998. Heterogeneous beliefs and routes to chaos in a simple asset pricing model. Journal of Economic Dynamics and Control 22, 1235-1274.

Brown, K. Harlow, W., and Starks, L., 1996. Of tournaments and temptations: an analysis of managerial incentives in the mutual fund industry. Journal of Finance 51, 85-110.

Brown, K., Harlow, W., and Zhang, H., 2011. Investment style volatility and mutual fund performance. Working paper.

Budiono, D. and Martens, M, 2010. Mutual fund style timing skills and alpha. Working paper.

Carhart, M.M., 1997. On persistence in mutual fund performance. Journal of Finance 52, 5782.

Chan, L. K. Chen, H.-L. and Lakonishok, J., 2002. On mutual fund investment styles. Review of Financial Studies 15, 1407-1437. 
Choe, H., Kho, B.C. and R. Stulz, 1999. Do foreign investors destabilize stock markets? Journal of Financial Economics 54, 227-264.

Fama, E.F. and K.R. French, 1993. Common risk factors in the returns on stocks and bonds. Journal of Financial Economics 33, 3-56.

Froot, K., O'Connell, P. and M. Seasholes, 2001. The portfolio flows of international investors. Journal of Financial Economics 59, 149-193.

Froot, K. and Teo, M., 2008. Style investing and institutional investors. Journal of Financial and Quantitative Analysis 43, 883-906.

Goetzman, W. and Massa, M., 2002. Daily momentum and contrarian behaviour of index fund investors. Journal of Financial and Quantitative Analysis 37, 375-389.

Grinblatt, M., Titman, S., and Wermers, R. (1995). Momentum Investment Strategies, Portfolio Performance, and Herding: A Study of Mutual Fund Behavior, American Economic Review 85, 10881105.

Jegadeesh, N. and S. Titman, 1993. Returns to buying winners and selling losers: Implications for stock market efficiency. Journal of Finance 48, 65-91.

Keim, D.B. and A. Madhavan, 1995. Anatomy of the trading process: Empirical evidence on the behavior of institutional investors. Journal of Financial Economics 37, 371-398.

Manski, C. F. and McFadden, D., 1981. Structural analysis of discrete data with econometric applications. MIT Press, Cambridge, MA.

Rouwenhorst, K.G., 1998. International momentum strategies. Journal of Finance 53, 267284. 
Sirri, E. and Tufano, P., 1998. Costly search and mutual fund flows. Journal of Finance 53, 1589-1662.

Swinkels, L., and Tjong-a-Tjoe, L., 2007. Can mutual funds time investment styles? Journal of Asset Management 8, 123-132.

Teo, M. and Woo, S.-J., 2004. Style effects in the cross-section of stock returns. Journal of Financial Economics 74, 367-398.

Wermers, R. (2012). Matter of Style: The Causes and Consequences of Style Drift in Institutional Portfolios, Working Paper, University of Maryland. 
Table 1. Mutual Fund Descriptive Statistics

\begin{tabular}{|c|c|c|c|c|c|c|}
\hline & \multirow[b]{2}{*}{ \# FUNDS } & \multicolumn{5}{|c|}{ MEDIANS } \\
\hline & & RETURN & STDEV & MIN & MAX & \# OBS \\
\hline LCVE & 128 & $0.686 \%$ & $4.860 \%$ & $-18.108 \%$ & $9.716 \%$ & 125 \\
\hline LCCE & 208 & $0.667 \%$ & $4.931 \%$ & $-18.049 \%$ & $9.471 \%$ & 104.5 \\
\hline LCGE & 128 & $0.530 \%$ & $5.535 \%$ & $-19.438 \%$ & $11.213 \%$ & 114 \\
\hline MLVE & 239 & $0.663 \%$ & $4.973 \%$ & $-19.787 \%$ & $10.498 \%$ & 122 \\
\hline MLCE & 326 & $0.731 \%$ & $5.034 \%$ & $-18.970 \%$ & $9.999 \%$ & 89.5 \\
\hline MLGE & 184 & $0.756 \%$ & $6.253 \%$ & $-22.262 \%$ & $13.280 \%$ & 124 \\
\hline MCVE & 96 & $0.916 \%$ & $5.567 \%$ & $-23.026 \%$ & $13.138 \%$ & 112.5 \\
\hline MCCE & 120 & $0.976 \%$ & $6.041 \%$ & $-24.471 \%$ & $13.473 \%$ & 98 \\
\hline MCGE & 145 & $0.848 \%$ & $7.225 \%$ & $-25.184 \%$ & $17.658 \%$ & 93 \\
\hline SCVE & 163 & $0.943 \%$ & $6.006 \%$ & $-23.089 \%$ & $13.940 \%$ & 123 \\
\hline SCCE & 168 & $1.024 \%$ & $6.462 \%$ & $-23.409 \%$ & $14.662 \%$ & 92 \\
\hline SCGE & 139 & $0.944 \%$ & $7.536 \%$ & $-26.892 \%$ & $20.709 \%$ & 110 \\
\hline
\end{tabular}


Table 2. Fund Characteristics

\begin{tabular}{|c|c|c|c|c|c|c|c|c|c|c|c|c|c|}
\hline & ALL & LCVE & LCCE & LCGE & MLVE & MLCE & MLGE & MCVE & MCCE & MCGE & SCVE & SCCE & SCGE \\
\hline & \multicolumn{13}{|c|}{ Total Expense Ratio } \\
\hline Mean & $1.41 \%$ & $1.26 \%$ & $1.32 \%$ & $1.43 \%$ & $1.35 \%$ & $1.25 \%$ & $1.49 \%$ & $1.39 \%$ & $1.39 \%$ & $1.65 \%$ & $1.47 \%$ & $1.45 \%$ & $1.62 \%$ \\
\hline Std Dev & $0.53 \%$ & $0.51 \%$ & $0.51 \%$ & $0.54 \%$ & $0.49 \%$ & $0.55 \%$ & $0.54 \%$ & $0.42 \%$ & $0.57 \%$ & $0.58 \%$ & $0.43 \%$ & $0.50 \%$ & $0.41 \%$ \\
\hline Perc. 5\% & $0.51 \%$ & $0.47 \%$ & $0.56 \%$ & $0.68 \%$ & $0.53 \%$ & $0.20 \%$ & $0.75 \%$ & $0.79 \%$ & $0.40 \%$ & $0.91 \%$ & $0.96 \%$ & $0.57 \%$ & $1.04 \%$ \\
\hline Perc. $50 \%$ & $1.35 \%$ & $1.17 \%$ & $1.25 \%$ & $1.30 \%$ & $1.26 \%$ & $1.26 \%$ & $1.45 \%$ & $1.29 \%$ & $1.39 \%$ & $1.55 \%$ & $1.40 \%$ & $1.41 \%$ & $1.50 \%$ \\
\hline \multirow[t]{2}{*}{ Perc. 95\% } & $2.27 \%$ & $2.08 \%$ & $2.17 \%$ & $2.28 \%$ & $2.17 \%$ & $2.14 \%$ & $2.34 \%$ & $2.15 \%$ & $2.25 \%$ & $2.50 \%$ & $2.37 \%$ & $2.27 \%$ & $2.50 \%$ \\
\hline & \multicolumn{13}{|c|}{ Fund Age (in years) } \\
\hline Mean & 14.24 & 16.66 & 14.03 & 15.59 & 15.65 & 13.14 & 15.62 & 15.60 & 13.35 & 13.30 & 14.44 & 11.31 & 13.31 \\
\hline Std Dev & 10.52 & 14.56 & 12.56 & 11.74 & 12.19 & 10.04 & 12.07 & 9.26 & 8.89 & 9.85 & 6.73 & 5.41 & 6.80 \\
\hline Perc. 5\% & 5.00 & 4.91 & 4.47 & 4.24 & 5.22 & 4.78 & 4.26 & 5.42 & 5.21 & 5.16 & 5.29 & 5.42 & 5.34 \\
\hline Perc. $50 \%$ & 11.84 & 12.76 & 10.59 & 12.41 & 12.75 & 10.76 & 13.17 & 13.62 & 10.91 & 10.93 & 13.63 & 10.42 & 12.80 \\
\hline \multirow[t]{2}{*}{ Perc. 95\% } & 32.93 & 45.95 & 34.81 & 41.68 & 34.39 & 25.59 & 43.61 & 35.42 & 27.97 & 33.71 & 26.04 & 18.59 & 25.76 \\
\hline & \multicolumn{13}{|c|}{ Total Net Assets (in Millions) } \\
\hline Mean & 418.5 & 530.2 & 770.5 & 858.2 & 334.4 & 411.9 & 444.1 & 399.3 & 440.5 & 168.1 & 333.0 & 195.8 & 170.9 \\
\hline Std Dev & 1754.5 & 1348.2 & 4394.0 & 2584.5 & 766.5 & 1285.3 & 1302.1 & 656.4 & 1084.6 & 286.9 & 941.6 & 358.3 & 372.4 \\
\hline Perc. $5 \%$ & 15.1 & 16.1 & 14.2 & 14.2 & 15.0 & 13.8 & 15.3 & 18.8 & 17.2 & 14.3 & 16.4 & 15.9 & 15.0 \\
\hline Perc. $50 \%$ & 72.3 & 88.4 & 67.8 & 78.8 & 83.3 & 65.4 & 93.2 & 132.1 & 68.5 & 49.3 & 64.9 & 69.8 & 67.9 \\
\hline \multirow[t]{2}{*}{ Perc. 95\% } & 1598.5 & 2911.7 & 2056.7 & 6338.3 & 1573.7 & 2326.7 & 2243.4 & 1814.3 & 2937.0 & 755.3 & 1500.3 & 640.1 & 663.1 \\
\hline & \multicolumn{13}{|c|}{ Turnover (percentage of TNA) } \\
\hline Mean & $83.30 \%$ & $64.07 \%$ & $60.40 \%$ & $80.97 \%$ & $57.75 \%$ & $69.66 \%$ & $123.65 \%$ & $75.60 \%$ & $84.37 \%$ & $126.17 \%$ & $65.93 \%$ & $95.35 \%$ & $120.27 \%$ \\
\hline Std Dev & $93.87 \%$ & $81.84 \%$ & $43.81 \%$ & $87.17 \%$ & $38.76 \%$ & $77.42 \%$ & $162.61 \%$ & $89.03 \%$ & $82.29 \%$ & $93.00 \%$ & $76.41 \%$ & $133.09 \%$ & $63.67 \%$ \\
\hline Perc. 5\% & $11.50 \%$ & $7.00 \%$ & $4.00 \%$ & $16.00 \%$ & $14.00 \%$ & $4.50 \%$ & $21.00 \%$ & $11.00 \%$ & $17.00 \%$ & $28.00 \%$ & $17.00 \%$ & $19.00 \%$ & $46.50 \%$ \\
\hline Perc. $50 \%$ & $64.00 \%$ & $51.00 \%$ & $52.50 \%$ & $68.48 \%$ & $47.00 \%$ & $51.00 \%$ & $90.50 \%$ & $62.00 \%$ & $65.00 \%$ & $104.00 \%$ & $53.00 \%$ & $68.00 \%$ & $100.25 \%$ \\
\hline Perc. 95\% & $204.00 \%$ & $192.00 \%$ & $139.50 \%$ & $166.00 \%$ & $138.00 \%$ & $204.00 \%$ & $267.00 \%$ & $150.00 \%$ & $230.50 \%$ & $280.00 \%$ & $133.50 \%$ & $195.50 \%$ & $245.00 \%$ \\
\hline
\end{tabular}

Note: This Table presents summary statistics on fund characteristics. We present the values for the mean, standard deviation, and the $5 \%, 50 \%$, and $95 \%$ percentiles. We report statistics for the Total Expense Ratio, Fund Age, Total Net Assets, and Turnover for all funds and per fund category. 
Table 3. Descriptive Statistics for the Benchmark Portfolios

\begin{tabular}{|c|c|c|c|c|}
\hline & LV & LG & SV & SG \\
\hline \multicolumn{5}{|c|}{ Panel A: Descriptive Statistics } \\
\hline Mean & $1.073 \%$ & $0.816 \%$ & $1.424 \%$ & $0.827 \%$ \\
\hline Median & $1.325 \%$ & $0.920 \%$ & $1.760 \%$ & $1.055 \%$ \\
\hline Maximum & $21.090 \%$ & $21.260 \%$ & $30.270 \%$ & $28.880 \%$ \\
\hline Minimum & $-22.640 \%$ & $-23.230 \%$ & $-27.720 \%$ & $-32.340 \%$ \\
\hline Std. Dev. & $4.720 \%$ & $4.753 \%$ & $5.660 \%$ & $6.969 \%$ \\
\hline Skewness & -0.413 & -0.292 & $-0.377 \%$ & $-0.303 \%$ \\
\hline Kurtosis & 5.604 & 4.676 & 6.335 & 4.671 \\
\hline \multicolumn{5}{|c|}{ Panel B: Correlations } \\
\hline $\mathrm{LV}$ & 1.0000 & & & \\
\hline LG & 0.7825 & 1.0000 & & \\
\hline SV & 0.8512 & 0.7433 & 1.0000 & \\
\hline SG & 0.7117 & 0.8259 & 0.8838 & 1.0000 \\
\hline
\end{tabular}

Note: This Table presents descriptive statistics for the four benchmark portfolios. SV, SG, LV', and LG, represents small value, small growth, big value, and big growth, respectively. 
Table 4. Estimation results for the Oppenheimer Main Street Opportunity Fund

\begin{tabular}{|c|c|c|c|c|c|}
\hline & Static Model & Single $\gamma$ & Value twin style & Size twin style & Double twin styles \\
\hline \multirow[t]{2}{*}{$\beta^{L V}$} & 0.309 & 0.000 & -0.038 & 0.554 & 0.129 \\
\hline & $(0.913)$ & $(0.002)$ & $(-0.142)$ & $(1.601)$ & $(0.441)$ \\
\hline \multirow{2}{*}{$\beta^{L G}$} & $1.574 * * *$ & $2.253 * * *$ & $2.274 * * *$ & $1.756 * * *$ & $2.510 * * *$ \\
\hline & $(3.844)$ & $(3.631)$ & $(4.135)$ & $(4.221)$ & $(4.961)$ \\
\hline \multirow{2}{*}{$\beta^{S V}$} & $1.117 * * *$ & $0.975 * * *$ & $1.112 * * *$ & $0.838 * *$ & $0.824 * * *$ \\
\hline & $(3.238)$ & $(3.429)$ & $(4.310)$ & $(2.138)$ & $(2.896)$ \\
\hline \multirow{2}{*}{$\beta^{S G}$} & $0.598 *$ & 0.605 & 0.568 & $0.564^{*}$ & $0.573^{*}$ \\
\hline & $(1.886)$ & $(1.395)$ & $(1.560)$ & $(1.720)$ & (1.707) \\
\hline$\gamma$ & & $\begin{array}{c}0.021 * * * \\
(2.779)\end{array}$ & & & \\
\hline$\gamma^{B M}$ & & & $\begin{array}{c}0.013 * * * \\
(2.600)\end{array}$ & & $\begin{array}{c}0.011 * * \\
(2.557)\end{array}$ \\
\hline$\gamma^{S I Z E}$ & & & & $\begin{array}{c}0.024 \\
(1.201)\end{array}$ & $\begin{array}{c}0.025 \\
(0.020)\end{array}$ \\
\hline$\alpha$ & $\begin{array}{c}-0.130 \\
(-0.197)\end{array}$ & $\begin{array}{c}-0.129 \\
(-0.450)\end{array}$ & $\begin{array}{c}-0.194 \\
(-0.724)\end{array}$ & $\begin{array}{c}-0.098 \\
(-0.389)\end{array}$ & $\begin{array}{c}-0.143 \\
(-0.555)\end{array}$ \\
\hline Lag & & 12 & 12 & 12 & 12,12 \\
\hline LOGL & -254.43 & -251.07 & -251.67 & -253.54 & -250.38 \\
\hline $\mathrm{LR}^{\text {STATIC }}$ & & $6.720 * * *$ & $5.520 * *$ & 1.780 & $8.100 * * *$ \\
\hline $\mathrm{LR}^{\mathrm{BM}}$ & & & & & -2.580 \\
\hline $\mathrm{LR}^{\text {SIZE }}$ & & & & & $-6.320 * *$ \\
\hline
\end{tabular}

Note: This Table presents the estimation results of the static model (first column); the single switching model (second column); the twin style value switching model (third columns); the twin style size switching model (fourth columns); and the double twin style model (third column) for the Oppenheimer Main Street Opportunity Fund. White corrected t-statistics are reported in parentheses. LR is the outcome of a Likelihood Ratio test versus the static model. $\mathrm{LR}^{\mathrm{BM}}$ is the outcome of a Likelihood Ratio test of the twin style value model versus the double twin style model, and $\mathrm{LR}^{\mathrm{SIZE}}$ is the outcome of a Likelihood Ratio test of the twin style size model versus the double twin style model. We indicate significance at the $10 \%, 5 \%$ and $1 \%$ level, by *, **, and ***, respectively. 
Table 5. Percentage of Switching Funds

\begin{tabular}{|c|c|c|c|c|c|c|c|c|c|c|c|c|c|}
\hline & ALL & LCVE & LCCE & LCGE & MCVE & MCCE & MCGE & MLVE & MLCE & MLGE & SCVE & SCCE & SCGE \\
\hline & \multicolumn{13}{|c|}{ Panel A: Single $\gamma$ Model } \\
\hline Total & $52.56 \%$ & $50.45 \%$ & $47.90 \%$ & $44.33 \%$ & $68.67 \%$ & $50.98 \%$ & $57.69 \%$ & $52.15 \%$ & $52.79 \%$ & $49.38 \%$ & $48.46 \%$ & $50.75 \%$ & $60.83 \%$ \\
\hline Positive $\gamma$ & $22.61 \%$ & $12.84 \%$ & $13.77 \%$ & $20.62 \%$ & $18.07 \%$ & $21.57 \%$ & $40.77 \%$ & $11.96 \%$ & $27.51 \%$ & $41.36 \%$ & $2.31 \%$ & $16.42 \%$ & $43.33 \%$ \\
\hline \multirow[t]{2}{*}{ Negative $\gamma$} & $29.95 \%$ & $37.61 \%$ & $34.13 \%$ & $23.71 \%$ & $50.60 \%$ & $29.41 \%$ & $16.92 \%$ & $40.19 \%$ & $25.28 \%$ & $8.02 \%$ & $46.15 \%$ & $34.33 \%$ & $17.50 \%$ \\
\hline & \multicolumn{13}{|c|}{ Panel B1: Twin Styles - Only BM Switching } \\
\hline Total & $20.69 \%$ & $20.93 \%$ & $24.82 \%$ & $16.67 \%$ & $24.10 \%$ & $21.57 \%$ & $14.62 \%$ & $28.87 \%$ & $26.02 \%$ & $10.69 \%$ & $11.29 \%$ & $25.98 \%$ & $15.13 \%$ \\
\hline Positive $\gamma$ & $5.96 \%$ & $0.00 \%$ & $4.26 \%$ & $5.95 \%$ & $4.82 \%$ & $6.86 \%$ & $8.46 \%$ & $5.15 \%$ & $5.69 \%$ & $5.03 \%$ & $1.61 \%$ & $11.02 \%$ & $11.76 \%$ \\
\hline \multirow[t]{2}{*}{ Negative $\gamma$} & $14.73 \%$ & $20.93 \%$ & $20.57 \%$ & $10.71 \%$ & $19.28 \%$ & $14.71 \%$ & $6.15 \%$ & $23.71 \%$ & $20.33 \%$ & $5.66 \%$ & $9.68 \%$ & $14.96 \%$ & $3.36 \%$ \\
\hline & \multicolumn{13}{|c|}{ Panel B2: Twin Styles - Only Size Switching } \\
\hline Total & $17.62 \%$ & $25.58 \%$ & $12.06 \%$ & $8.33 \%$ & $24.10 \%$ & $22.55 \%$ & $13.85 \%$ & $10.82 \%$ & $14.23 \%$ & $19.50 \%$ & $29.84 \%$ & $16.54 \%$ & $24.37 \%$ \\
\hline Positive $\gamma$ & $9.03 \%$ & $18.60 \%$ & $6.38 \%$ & $2.38 \%$ & $10.84 \%$ & $11.76 \%$ & $10.77 \%$ & $6.19 \%$ & $7.72 \%$ & $13.84 \%$ & $0.81 \%$ & $7.09 \%$ & $15.97 \%$ \\
\hline \multirow[t]{2}{*}{ Negative $\gamma$} & $8.59 \%$ & $6.98 \%$ & $5.67 \%$ & $5.95 \%$ & $13.25 \%$ & $10.78 \%$ & $3.08 \%$ & $4.64 \%$ & $6.50 \%$ & $5.66 \%$ & $29.03 \%$ & $9.45 \%$ & $8.40 \%$ \\
\hline & \multicolumn{13}{|c|}{ Panel B3: Twin Styles - Double Switching } \\
\hline Total & $38.9 \%$ & $29.1 \%$ & $32.6 \%$ & $38.1 \%$ & $36.1 \%$ & $34.3 \%$ & $54.6 \%$ & $40.2 \%$ & $37.0 \%$ & $43.4 \%$ & $42.7 \%$ & $29.1 \%$ & $44.5 \%$ \\
\hline Pos Size - Pos BM & $8.84 \%$ & $5.81 \%$ & $5.67 \%$ & $3.57 \%$ & $6.02 \%$ & $4.90 \%$ & $18.46 \%$ & $10.82 \%$ & $7.72 \%$ & $16.35 \%$ & $4.03 \%$ & $3.15 \%$ & $13.45 \%$ \\
\hline Pos Size - Neg BM & $11.10 \%$ & $12.79 \%$ & $7.09 \%$ & $10.71 \%$ & $7.23 \%$ & $15.69 \%$ & $19.23 \%$ & $10.31 \%$ & $9.76 \%$ & $10.06 \%$ & $6.45 \%$ & $11.81 \%$ & $14.29 \%$ \\
\hline Neg Size - Pos BM & $9.84 \%$ & $4.65 \%$ & $6.38 \%$ & $11.90 \%$ & $10.84 \%$ & $4.90 \%$ & $13.08 \%$ & $7.22 \%$ & $11.38 \%$ & $8.81 \%$ & $18.55 \%$ & $7.09 \%$ & $12.61 \%$ \\
\hline \multirow[t]{2}{*}{ Neg Size - Neg BM } & $9.09 \%$ & $5.81 \%$ & $13.48 \%$ & $11.90 \%$ & $12.05 \%$ & $8.82 \%$ & $3.85 \%$ & $11.86 \%$ & $8.13 \%$ & $8.18 \%$ & $13.71 \%$ & $7.09 \%$ & $4.20 \%$ \\
\hline & \multicolumn{13}{|c|}{ Panel B4: Twin Styles - TOTAL } \\
\hline Total & $77.2 \%$ & $75.6 \%$ & $69.5 \%$ & $63.1 \%$ & $84.3 \%$ & $78.4 \%$ & $83.1 \%$ & $79.9 \%$ & $77.3 \%$ & $73.6 \%$ & $83.8 \%$ & $71.6 \%$ & $84.0 \%$ \\
\hline
\end{tabular}

Notes: This Table presents the percentage of funds for which we find significant switching. Specifically, we give the percentage of funds for which the likelihood ratio test indicates that switching adds significantly to the explanatory power of the model. Panel A represents results of the single switching model versus the static model; Panel B presents the results of the double switching model versus the static model; and Panel $\mathrm{C}$ presents the results of the single versus double switching model. 
Table 6. Relation between Style Switching and Fund Characteristics

\begin{tabular}{|c|c|c|c|c|c|c|c|c|c|}
\hline & \multicolumn{3}{|c|}{ Single Switching } & \multicolumn{6}{|c|}{ Double Switching } \\
\hline & \multicolumn{3}{|c|}{$\left|\gamma^{S I N G L E}\right|$} & \multicolumn{3}{|c|}{$\left|\gamma^{B M}\right|$} & \multicolumn{3}{|c|}{$\left|\gamma^{S I Z E}\right|$} \\
\hline & All & Pos & $\mathrm{Neg}$ & All & Pos & $\mathrm{Neg}$ & All & Pos & $\mathrm{Neg}$ \\
\hline \multirow[t]{2}{*}{$T E R$} & $0.344 * *$ & 0.199 & $0.372 * *$ & $0.469 * *$ & $0.785^{* *}$ & 0.190 & -0.379 & -0.422 & -0.390 \\
\hline & $(2.078)$ & $(0.674)$ & $(2.138)$ & $(2.189)$ & $(2.000)$ & $(0.827)$ & $(-0.882)$ & $(-0.606)$ & $(-0.823)$ \\
\hline \multirow[t]{2}{*}{$L O G(A G E)$} & $-0.006 * * *$ & $-0.006^{* *}$ & $-0.008 * * *$ & $-0.012 * * *$ & $-0.015 * * *$ & $-0.010 * * *$ & $-0.014 * * *$ & -0.003 & $-0.026 * * *$ \\
\hline & $(-4.939)$ & $(-2.268)$ & $(-4.867)$ & $(-6.480)$ & $(-5.179)$ & $(-4.487)$ & $(-4.498)$ & $(-0.756)$ & $(-6.780)$ \\
\hline \multirow[t]{2}{*}{$L O G(T N A)$} & 0.000 & -0.002 & $0.002^{* *}$ & 0.000 & -0.002 & 0.001 & -0.001 & -0.002 & 0.002 \\
\hline & $(0.365)$ & $(-1.541)$ & $(2.098)$ & $(0.289)$ & $(-1.135)$ & (1.014) & $(-1.490)$ & $(-0.896)$ & $(1.062)$ \\
\hline \multirow[t]{2}{*}{ TURNOVER } & 0.001 & $0.004 *$ & -0.001 & 0.001 & 0.002 & -0.001 & $0.006 * * *$ & $0.008 * * *$ & 0.003 \\
\hline & (1.033) & $(1.829)$ & $(-1.023)$ & $(0.640)$ & $(0.889)$ & $(-0.568)$ & $(2.945)$ & $(4.247)$ & $(0.628)$ \\
\hline \multirow[t]{2}{*}{$L A G$} & $-0.001 * * *$ & -0.001 & $-0.001 * * *$ & $-0.003^{* * *}$ & $-0.004 * * *$ & $-0.003 * * *$ & -0.001 & $-0.001 * *$ & -0.001 \\
\hline & $(-2.843)$ & $(-0.798)$ & $(-5.721)$ & $(-9.143)$ & $(-5.731)$ & $(-5.792)$ & $(-1.490)$ & $(-2.610)$ & $(-1.035)$ \\
\hline Style dummies & YES & YES & YES & YES & YES & YES & YES & YES & YES \\
\hline Adj. $R^{2}$ & 0.070 & 0.066 & 0.135 & 0.136 & 0.162 & 0.108 & 0.065 & 0.088 & 0.085 \\
\hline \#OBS & 1878 & 838 & 1040 & 1807 & 796 & 1011 & 1807 & 901 & 906 \\
\hline
\end{tabular}

Notes: This Table reports the regression results for Equation (9). $\left|\gamma^{\text {SINGLE }}\right|$ is the absolute value of the style switching coefficient in the single switching model (Equations (5) and (6)); $\left|\gamma^{S I Z E}\right|$ and $\left|\gamma^{B M}\right|$ are the absolute values of the style switching coefficients in the double switching model (Equations (7) and (8)); $\log \left(\operatorname{Ag}_{i}\right)$ is the $\log$ of the age of the fund; $\log \left(T N A_{i}\right)$ is the $\log$ of the beginning of period size of the fund; Turnover $_{i}$ is the median share turnover of the fund; and $T E R_{i}$ is the total expense ratio of the fund. In each regression, we include dummy variables to control for the stated fund style (not reported). We report White corrected t-statistics in parentheses. We indicate significance at the $10 \%, 5 \%$ and $1 \%$ level, by $* * *$, and $* * *$, respectively. 
Table 7. Risk-Adjusted Performance and Style Switching

\begin{tabular}{|c|c|c|c|}
\hline & $\gamma^{\prime S I N G L E}$ & $\gamma^{B M}$ & $\gamma^{\prime S I Z E}$ \\
\hline \multicolumn{4}{|c|}{ Panel A: Interaction between Style Switching and Lags } \\
\hline & $0.712 * *$ & $0.492 * * *$ & 0.196 \\
\hline$\gamma+$ & $(2.367)$ & $(2.721)$ & $(0.763)$ \\
\hline & $-0.072 * *$ & -0.034 & -0.016 \\
\hline$\gamma+\gamma^{\prime} \operatorname{Lag}$ & $(-2.145)$ & $(-0.938)$ & $(-0.517)$ \\
\hline & 0.303 & 0.068 & -0.052 \\
\hline$\gamma-$ & $(1.376)$ & $(0.430)$ & $(-0.261)$ \\
\hline$\gamma-* \operatorname{Lag}$ & $\begin{array}{c}-0.086 * * * \\
(-3.389)\end{array}$ & $\begin{array}{c}-0.007 \\
(-0.223)\end{array}$ & $\begin{array}{c}-0.012 \\
(-0.368)\end{array}$ \\
\hline $\log (A g e)$ & $\begin{array}{c}-0.051 * * * \\
(-3.832)\end{array}$ & $\begin{array}{c}-0.057 * * * * \\
(-4.101)\end{array}$ & $\begin{array}{c}-0.056 * * * \\
(-4.199)\end{array}$ \\
\hline $\log (T N A)$ & $\begin{array}{c}-0.019 * * \\
(2.547)\end{array}$ & $\begin{array}{c}-0.017 * * \\
(-2.290)\end{array}$ & $\begin{array}{c}-0.018 * * \\
(-2.471)\end{array}$ \\
\hline Turnover & $\begin{array}{c}-0.036 * * * \\
(-3.476)\end{array}$ & $\begin{array}{c}-0.039 * * * \\
(-3.520)\end{array}$ & $\begin{array}{c}-0.037 * * * \\
(-3.431)\end{array}$ \\
\hline & $-7.557 * * *$ & $-7.540 * * *$ & $-7.582 * * *$ \\
\hline TER & $(-4.810)$ & $(-4.934)$ & $(-5.007)$ \\
\hline Style dummies & YES & YES & YES \\
\hline$R^{2}(a d j)$ & 0.091 & 0.124 & 0.078 \\
\hline \multicolumn{4}{|c|}{ Panel B: Piecewise Linear Relation between Style Switching and Lags } \\
\hline & 0.206 & -0.040 & -0.240 \\
\hline$\gamma_{1}$ & $(1.317)$ & $(-0.247)$ & $(-1.112)$ \\
\hline & 0.109 & 0.112 & $-0.065 * *$ \\
\hline$\gamma_{2}$ & $(0.266)$ & $(0.277)$ & $(-2.147)$ \\
\hline$\gamma^{+}$ & $-0.605 * *$ & -0.241 & $-0.046 * * *$ \\
\hline$\gamma_{3}$ & $(-2.478)$ & $(-1.547)$ & $(-2.786)$ \\
\hline & $-0.067 * * *$ & -0.064 & -0.007 \\
\hline$\gamma_{4}$ & $(-5.829)$ & $(-1.455)$ & $(-0.145)$ \\
\hline & $0.581 * *$ & $0.515 * * *$ & -0.005 \\
\hline$\gamma_{1}$ & $(2.525)$ & $(4.088)$ & $(-0.034)$ \\
\hline & -0.100 & $0.165 *$ & $-0.111 * *$ \\
\hline$\gamma_{2}$ & $(-0.801)$ & (1.803) & $(-2.207)$ \\
\hline & $0.134 * *$ & $0.235 * *$ & $0.095^{* *}$ \\
\hline$\sqrt{3}$ & $(2.108)$ & $(2.332)$ & $(2.232)$ \\
\hline & -0.083 & 0.034 & -0.006 \\
\hline$\gamma_{4}$ & $(-1.232)$ & $(0.429)$ & $(-0.352)$ \\
\hline $\log (A g e)$ & $-0.050 * * *$ & $-0.061 * * *$ & $-0.052 * * *$ \\
\hline & $(-3.679)$ & $(-4.397)$ & $(-3.905)$ \\
\hline $\log (T N A)$ & $-0.019 * *$ & $-0.017 * *$ & $-0.019 * * *$ \\
\hline & $(2.509)$ & $(2.395)$ & $(-2.605)$ \\
\hline Turnover & $-0.036 * * *$ & $-0.039 * * *$ & $-0.038 * * *$ \\
\hline & $(-3.665)$ & $(-3.541)$ & $(-3.482)$ \\
\hline TER & $-7.057 * * *$ & $-7.343^{* * *}$ & $-7.269 * * *$ \\
\hline & $(-4.431)$ & $(-4.807)$ & $(-0.953)$ \\
\hline Style dummies & YES & YES & YES \\
\hline$R^{2}(a d j)$ & 0.095 & 0.091 & 0.083 \\
\hline
\end{tabular}

Notes: This Table displays the estimation results of Equation (10). $\gamma^{\text {SINGLE }}$ is the style switching coefficient in the single switching model (Equations (5) and (6)); $\gamma^{S I Z E}$ and $\gamma^{B M}$ are the style switching coefficients in the double switching model (Equations (7) and (8)). $\gamma_{i}^{+}$and $\gamma_{i}^{-}$are the style switching parameters for positive feedback trading and negative feedback trading, respectively; $\gamma_{1}^{+}, \gamma_{2}^{+}, \gamma_{3}^{+}, \gamma_{4}^{+}$, and $\gamma_{1}^{-}, \gamma_{2}^{-}, \gamma_{3}^{-}, \gamma_{4}^{-}$as the positive and negative switching parameters for lags less than 3 months, between 4 and 6 months, between 7 and 9 , and 10 and 12 months, respectively; $\log \left(A g e_{i}\right)$ is the $\log$ of the age of the fund; $\log \left(T N A_{i}\right)$ is the $\log$ of the beginning of period size of the fund; Turnover $_{i}$ is the median share turnover of the fund; and $T E R_{i}$ is the total expense ratio of the fund. In each regression we include dummy variables to control for the stated fund style (not reported). We report White corrected t-statistics in parentheses. We indicate significance at the $10 \%, 5 \%$ and $1 \%$ level, by $*, * *$, and $* * *$, respectively. 
Figure 1. Unconditional Loadings on the Different Investment Styles

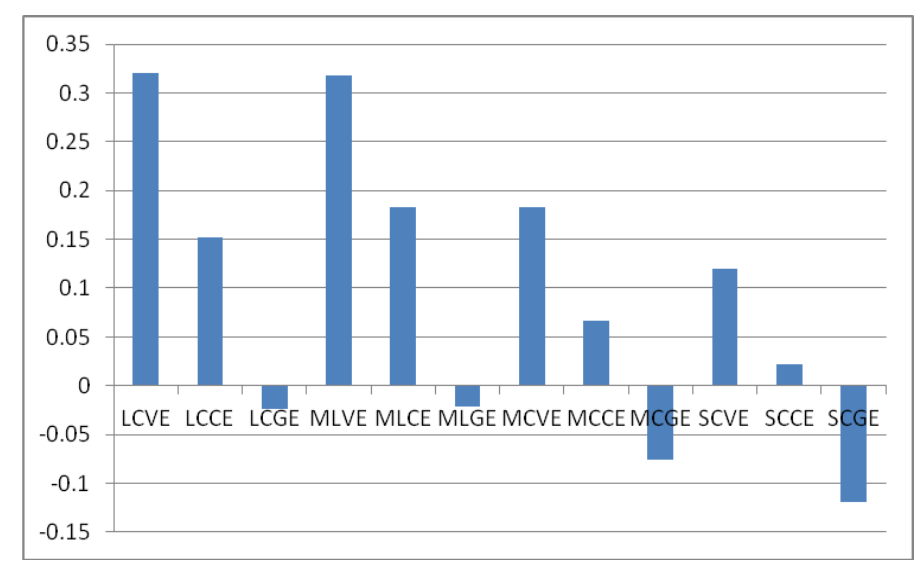

Exposure to Large-Value

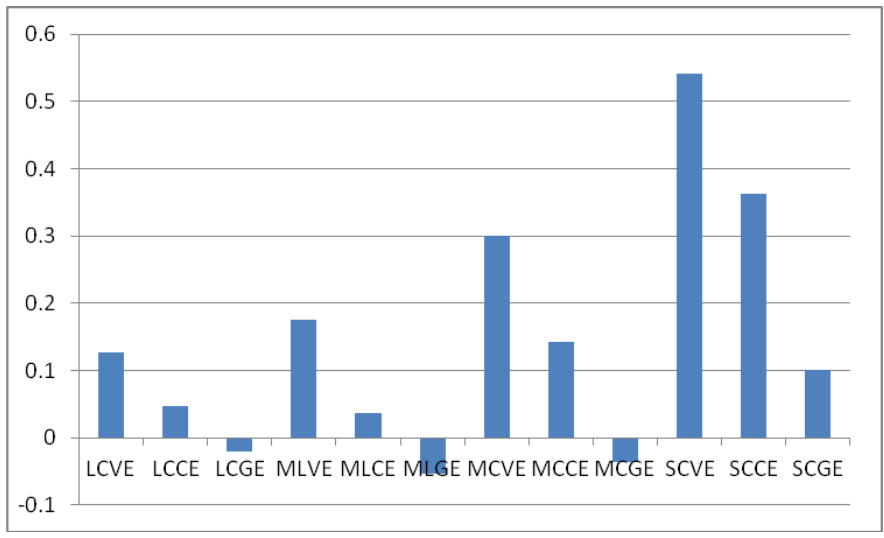

Exposure to Small-Value

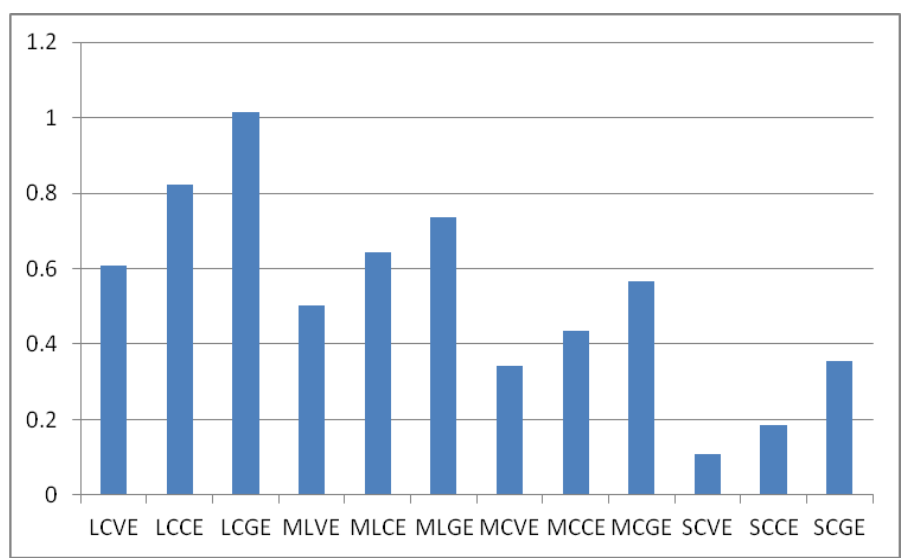

Exposure to Large-Growth

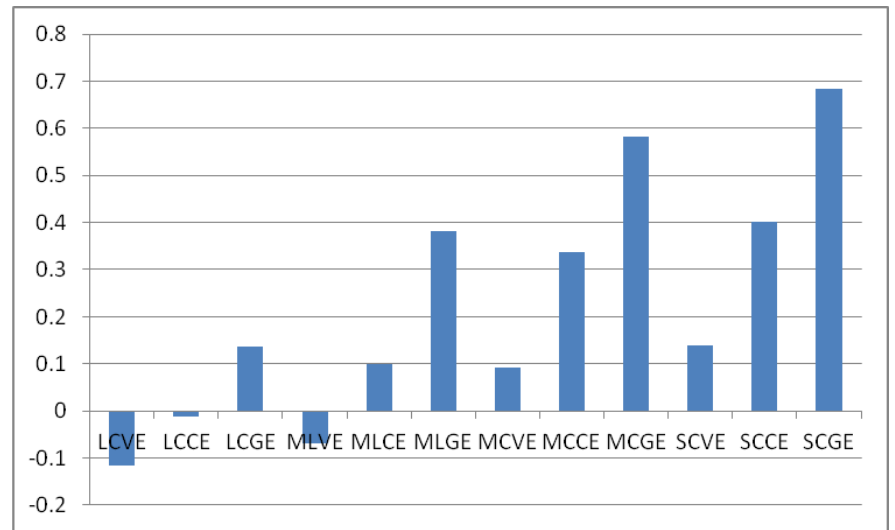

Exposure to Small-Growth

Notes: Figure 1 displays the average loadings to the four benchmark portfolios (y-axis) within the 12 fund classes (x-axis), estimated from Equation (4). 
Figure 2. Scatter Plot of Profit Difference versus Weight: Oppenheimer

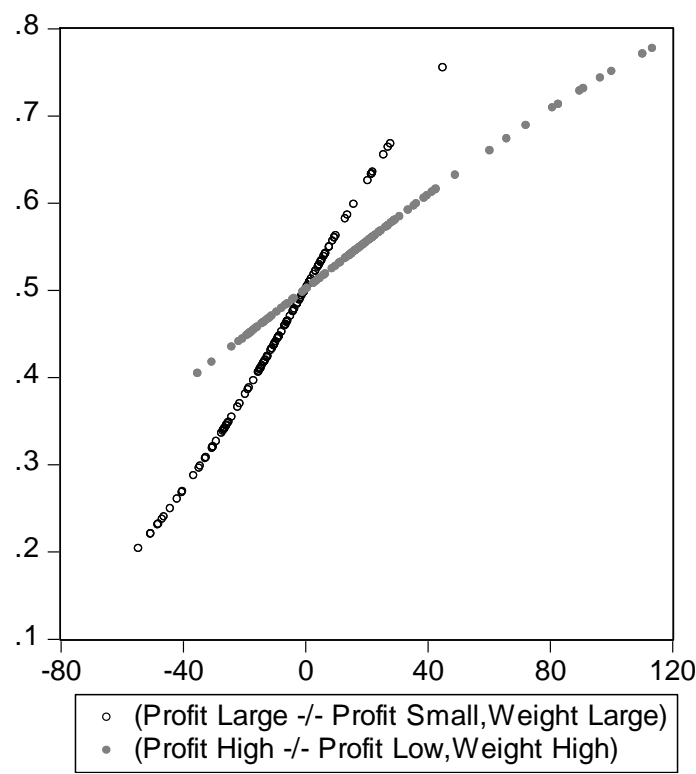

Notes: Figure 2 depicts a scatter plot of the profit difference (x-axis) versus the weight (y-axis) for the Oppenheimer fund, for both the size-switching and the book-to-market switching.

Figure 3. Time Series of Profit Differences and Weights: Oppenheimer

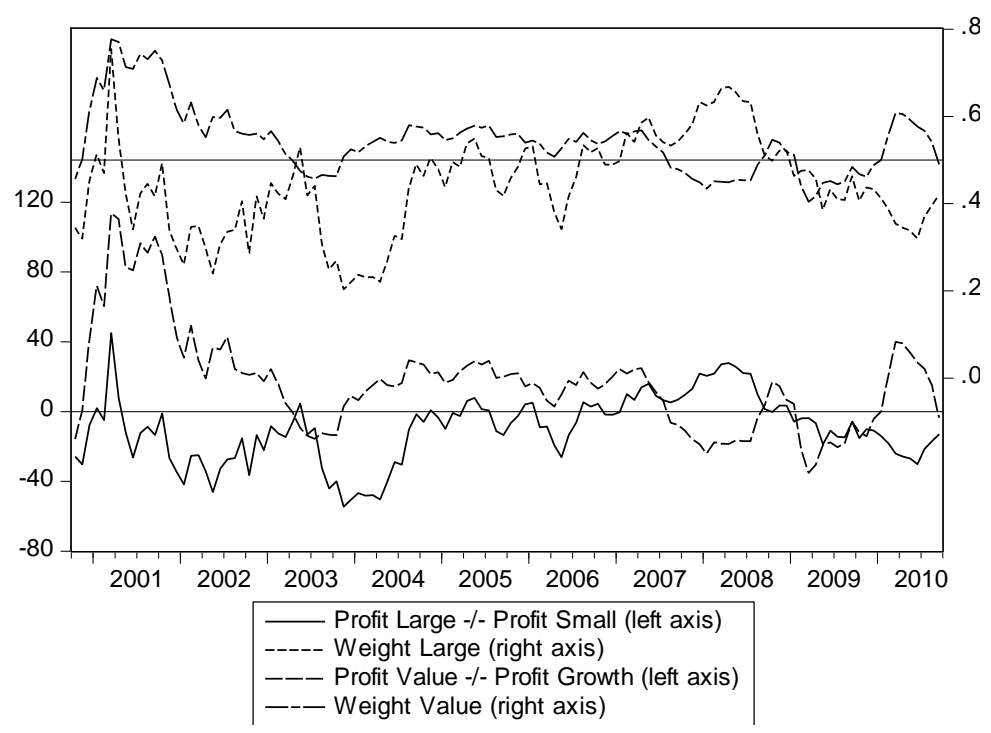

Notes: Figure 3 gives the time-series of the profit differences and the weights for the Oppenheimer Funds. 
Figure 4. Time Series of Conditional Exposures $w_{i t} \beta_{i}{ }^{k}$ : Oppenheimer
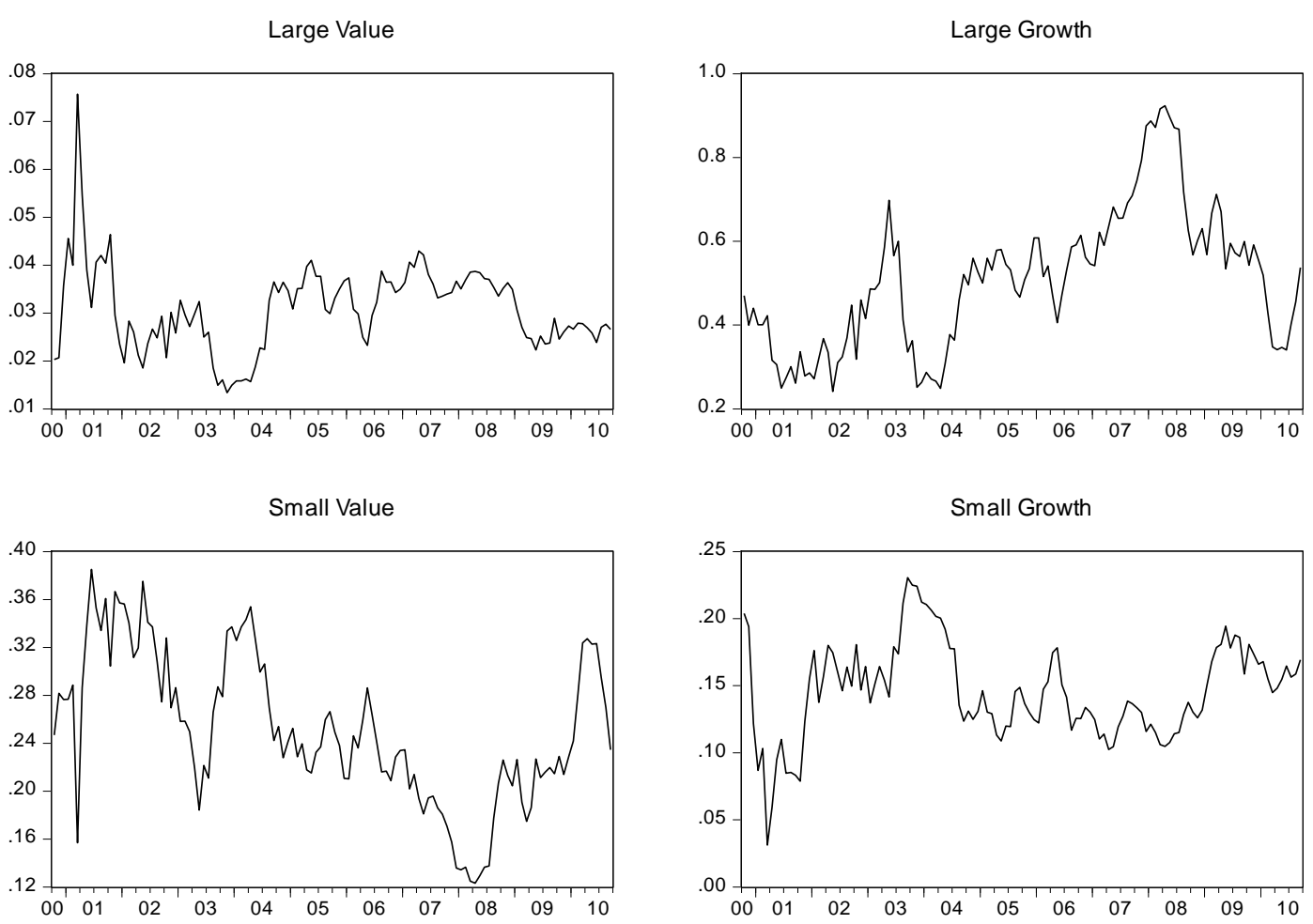

Notes: Figure 4 displays the conditional exposures, given by $w_{i} \beta_{i}^{k}$, to the four benchmark portfolios. 